\title{
Representation of Women Physician Deans in U.S. Medical Schools
}

\author{
Allison R. Larson, MD, ${ }^{1}$ Carolyn K. Kan, MPH, ${ }^{2}$ and Julie K. Silver, MD ${ }^{3}$
}

\begin{abstract}
Background: Among U.S. medical school deans, there is a wide gender gap, most prominent at the highest levels. We aimed to discover how well women physicians were represented within the pool of women deans compared with the pool of men deans.

Materials and Methods: A cross-sectional study was performed on 149 allopathic medical schools in the United States. For each school, information was collected on deans' names, titles, genders, and degree(s). Chi-square analyses were performed to determine association between gender and dean ranks.

Results: Of the 2559 deans included from 149 medical schools, 1649 (64.4\%) were physicians, and of these, women physicians accounted for $634(38.4 \%)$, a significant under-representation $(p<0.00001)$. In comparison, the 626 nonphysician doctorate-holders of which women accounted for $291(46.5 \%, p=0.061)$ were equally represented. Of the 284 deans with bachelor's or master's degrees, women accounted for 180 (63.4\%), a significant over-representation $(p<0.00001)$. This difference was most profound at the lower tier (assistant) dean level. A lower tier physician dean was 1.25 times more likely to be a man than a woman, and a higher tier (dean of medical school, senior associate, vice, or associate) physician dean was 1.16 times more likely to be a man.
\end{abstract}

Conclusions: Women physicians were under-represented among medical school deans compared with men. This disparity held among lower tier and higher tier deans.

Keywords: dean, gender gap, decanal

\section{Introduction}

$\mathbf{T}$ HE UNDER-REPRESENTATION of women in U.S. medical leadership has been well documented. Although there are signs of overall improvement in gender balance, it is not clear whether women physicians are advancing since studies often include both physicians and nonphysicians. Regarding leadership positions, it is important to understand whether advances in gender equity extend to a subset of women in medicine-women physicians.

There are few published gender studies on the topic of medical school deans. White et al. analyzed 534 full and interim deans (496 men, 38 women) between 1980-2006, and found that women were more likely to hold decanal positions in less research-intense medical schools. ${ }^{1} \mathrm{Re}$ cently, Schor found that women made up $44 \%$ of decanal positions nationwide, ${ }^{2}$ including all ranks of dean. However, this study did not investigate the proportion of women physician deans. At the highest level, the percentage of women as deans (or interim deans) of medical schools was 15. ${ }^{1}$ Notably, Schor found that there were differences in the types of decanal roles held by women-they were represented in greater proportions in areas focused on education, mentoring, and institutional image, as opposed to general, clinical, research, and corporate decision-making roles. ${ }^{2}$

Physician workforce gender equity in academic medicine has been slow. ${ }^{3}$ Given that in the United States, $>50 \%$ of matriculating medical students are now women ${ }^{4}$ and there are many well-documented gaps for physicians in promotion, ${ }^{5}$ compensation, ${ }^{6}$ and recognition awards, ${ }^{7}$ it is important to evaluate not only the under-representation of women in medical leadership roles but more specifically gaps in women physicians in these roles. The term "gender" is used throughout this report as "sex" is biologically determined and was not evaluated. For similar reasons, we used the terms "women physicians" and "men physicians" rather than "female physicians" and "male physicians."

${ }^{1}$ Department of Dermatology, Boston University, Boston, Massachusetts.

${ }^{2}$ Boston University School of Medicine, Boston, Massachusetts.

${ }^{3}$ Department of Physical Medicine and Rehabilitation, Harvard Medical School, Massachusetts General Hospital, Boston, Massachusetts. 
In this study, we analyzed the overall proportion of women physicians compared with all women deans and similarly assessed men physicians compared with all men deans. The gender distribution of deans at various levels was also analyzed. We hypothesized that women deans were less likely to be physicians compared with men deans. To our knowledge, this is the first study to assess the gender of medical school deans in various decanal categories (e.g., beyond the primary or interim dean) in addition to investigating whether women physicians (vs. nonphysicians) are represented in lower proportions compared with a similar analysis of men.

\section{Materials and Methods}

\section{Study design}

A total of 149 allopathic medical schools in the United States, including Puerto Rico, were included in this study. Medical schools anticipating an inaugural matriculating class in 2018 or later were excluded. The Association of American Medical Colleges was queried to obtain data on titles, genders, and professional degrees of all deans at U.S. medical schools, but this request was declined. Thus, data collection consisted of searches on medical school websites for the terms "dean," "vice dean," "associate dean," "assistant dean," and "leadership." These searches were performed between December 2017 and January 2018. Individuals listed as occupying a dean position were recorded, along with their gender and degree(s). For data consistency, only individuals holding the titles of dean of a medical school, vice dean, senior associate dean, associate, assistant dean, or an interim of one of these positions were included (Fig. 1).

If the degree(s) were not listed on the medical school website, an internet search was conducted to identify biographical articles, clinical practice sites, or LinkedIn profiles that contained this information. We investigated any duplicate names in our database to ensure that each individual was recorded in only their current position.

To determine gender, priority was given to biographical articles containing pronouns, which were found online for $95 \%$ of the individuals included in the study. In the absence of these, names and photographs were used to determine an individual's gender identity, a method used in prior decanal studies. $^{2}$

Individuals without pronouns or photographs were eliminated (Fig. 1). Deans denoted as physicians held an MD or equivalent degree (e.g., DO, MBBS, MB/ChB). All information collected was publicly available. This study was classified as nonhuman subjects research by the Boston University Medical Center institutional review board, and because all data were publicly available, an exemption was not required.

For ease of analysis, we categorized our data into three decanal tiers. Dean represents a dean or interim dean of a medical school. The higher tier dean category includes vice deans, senior associate deans, and associate deans. The lower tier dean category includes the assistant deans. Interim deans were included in each category as well.

\section{Outcomes and statistical analysis}

All statistical analyses were computed with the R v3.4.0 statistical programming language (R Core Team, Vienna, Austria). Chi-square tests were used to compare the propor-

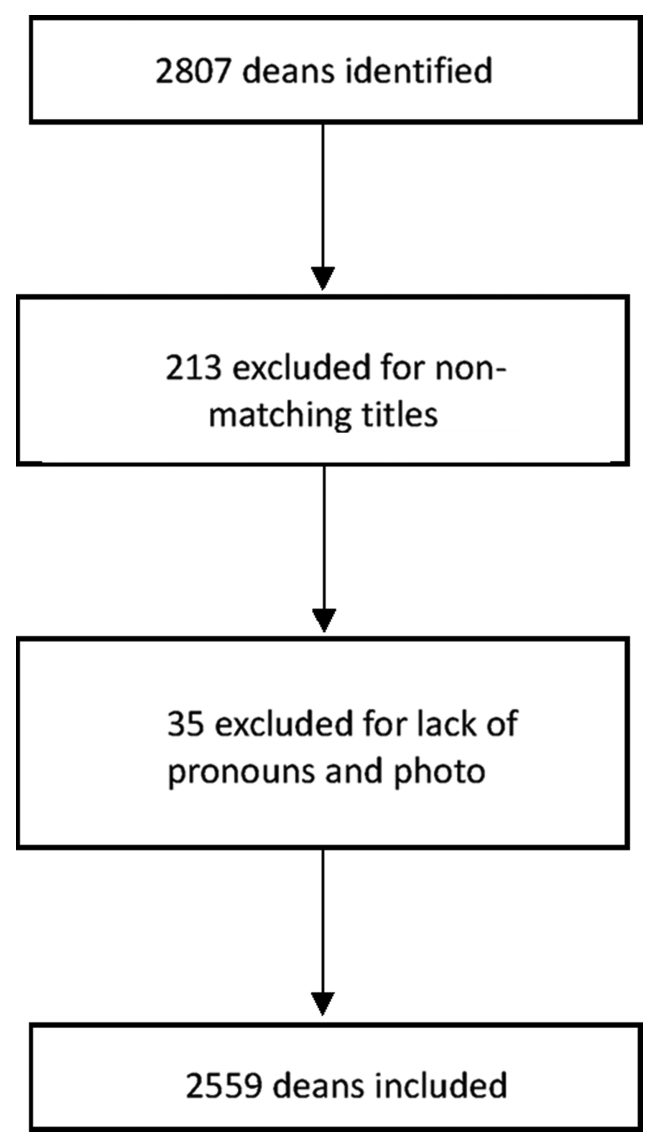

FIG. 1. Numbers of deans excluded for titles not matching those used in this analysis or for lacking online pronouns and photograph.

tions of women versus men holding each category of terminal degree (MD or equivalent, $\mathrm{PhD}$ or JD or other doctorate, or master's degree). Bachelor's degrees were included for deans who did not have a graduate degree. Chi-square tests were also used to compare the proportion of physicians among the group of women deans with the proportion of physicians among men deans. Similarly, the proportion of physicians among women and men in lower and higher tier dean categories were compared. A $p$-value of 0.0026 was considered significant, after applying the Bonferroni method to a threshold of 0.05 , to adjust for multiple comparisons.

\section{Results}

A total of 2559 qualifying deans within the 149 U.S. allopathic medical schools were included in this study (Fig. 1). The proportions of women with each category of terminal degree (MD or equivalent; $\mathrm{PhD}$, JD, or other doctorate; master's or bachelor's) were compared with the proportion of men in the same terminal degree category. Of the 2559 deans, $1649(64.4 \%)$ were physicians and of these, women accounted for $38.4 \%(n=634 / 1649)$ (Table 1; Fig. 2), a significant under-representation $(p<0.00001)$. In comparison, the 626 nonphysician doctorate-holders, of which women accounted for $291(46.5 \%, p=0.061)$, were equally represented. Of the 284 deans with bachelor's or master's degrees, women accounted for 180 (63.4\%), a significant 
Table 1. Number of U.S. Allopathic Deans in 2017 Stratified by Gender and Terminal Degree

\begin{tabular}{|c|c|c|c|c|}
\hline & Total & $M D(\%)$ & Other doctorate (\%) & Bachelor's or master's (\%) \\
\hline \multicolumn{5}{|l|}{ Dean } \\
\hline Total & 148 & $146(98.6)$ & $2(1.4)$ & $0(0)$ \\
\hline Men & 120 & $118(98.3)$ & $2(1.7)$ & $0(0)$ \\
\hline Women & 28 & $28(100)$ & $0(0)$ & $0(0)$ \\
\hline$p$-Value* & & 1.0 & & \\
\hline \multicolumn{5}{|l|}{ Vice dean } \\
\hline Total & 170 & $115(67.6)$ & $38(22.4)$ & $17(10.0)$ \\
\hline Men & 104 & $71(68.3)$ & $23(22.1)$ & $10(9.6)$ \\
\hline Women & 66 & $44(66.7)$ & $15(22.7)$ & 7 (10.6) \\
\hline$p$-Value* & & 0.96 & 1.0 & 1.0 \\
\hline \multicolumn{5}{|c|}{ Senior associate dean } \\
\hline Total & 312 & $206(66.0)$ & $72(23.1)$ & $34(10.9)$ \\
\hline Men & 193 & $133(68.9)$ & $45(23.3)$ & $15(7.8)$ \\
\hline Women & 119 & $73(61.3)$ & $27(22.7)$ & $19(16.0)$ \\
\hline$p$-Value & & 0.21 & 1.0 & 0.039 \\
\hline \multicolumn{5}{|c|}{ Associate dean } \\
\hline Total & 1185 & $763(64.4)$ & $292(24.6)$ & $130(11.0)$ \\
\hline Men & 658 & $456(69.3)$ & $150(22.8)$ & $52(7.9)$ \\
\hline Women & 527 & $307(58.3)$ & $142(26.9)$ & $78(14.8)$ \\
\hline$p$-Value* & & 0.00010 & 0.11 & 0.00023 \\
\hline \multicolumn{5}{|c|}{ Assistant dean } \\
\hline Total & 744 & $419(56.3)$ & $222(29.8)$ & 103 (13.9) \\
\hline Men & 379 & $237(62.5)$ & $115(30.4)$ & $27(7.1)$ \\
\hline Women & 365 & $182(49.9)$ & $107(29.3)$ & $76(20.8)$ \\
\hline$p$-Value* & & 0.00065 & 0.82 & $<0.00001$ \\
\hline \multicolumn{5}{|l|}{ All deans } \\
\hline Total & 2559 & $1649(64.4)$ & $626(24.5)$ & $284(11.1)$ \\
\hline Men & 1454 & $1015(69.8)$ & $335(23.0)$ & $104(7.2)$ \\
\hline Women & 1105 & $634(57.4)$ & $291(26.3)$ & $180(16.3)$ \\
\hline$p$-Value* & & $<0.00001$ & 0.061 & $<0.00001$ \\
\hline
\end{tabular}

$p$-Values compare the proportion of women deans with a particular degree to the proportion of men deans with the same degree. $* p<0.0026$.

over-representation $(p<0.00001)$. This difference was most profound at the associate and assistant dean levels (Table 1).

We grouped the deans into three categories: dean of the medical school, higher tier and lower tier deans (Fig. 3). Lower tier were the assistant deans; higher tier included the vice, senior associate, and associate deans. Women were represented in greater proportions among lower tier deans, and constituted $43.4 \%$ of physicians, $48.2 \%$ of nonphysician doctorate-holders, and $73.8 \%$ of those with bachelor's or master's degrees. In comparison, within the pool of higher tier deans, women made up $39.1 \%$ of physicians, $45.8 \%$ of nonphysician doctorate-holders, and $57.5 \%$ of those with bachelor's or master's degrees. A lower tier physician dean was 1.25 times more likely to be a man than a woman $(p=0.00065)$ (Table 2). A higher tier physician dean was 1.16 times more likely to be a man $(p=0.000064)$.

\section{Discussion}

Our study shows that despite nearly half of assistant and associate dean positions being held by women, the proportions of women physicians are significantly under-
FIG. 2. Among the group of deans, the percentage of physicians are represented in blue, stratified by gender. Color images are available online.

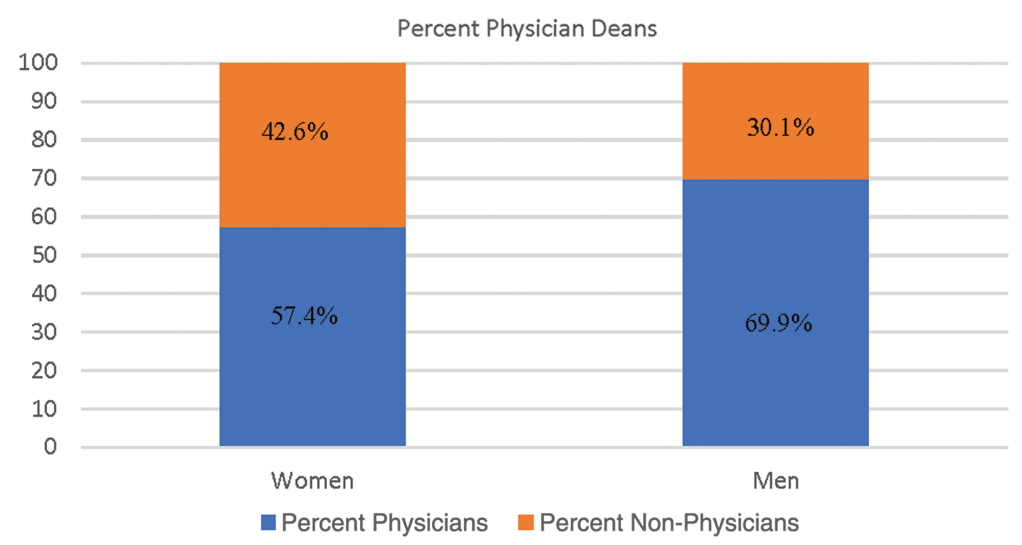




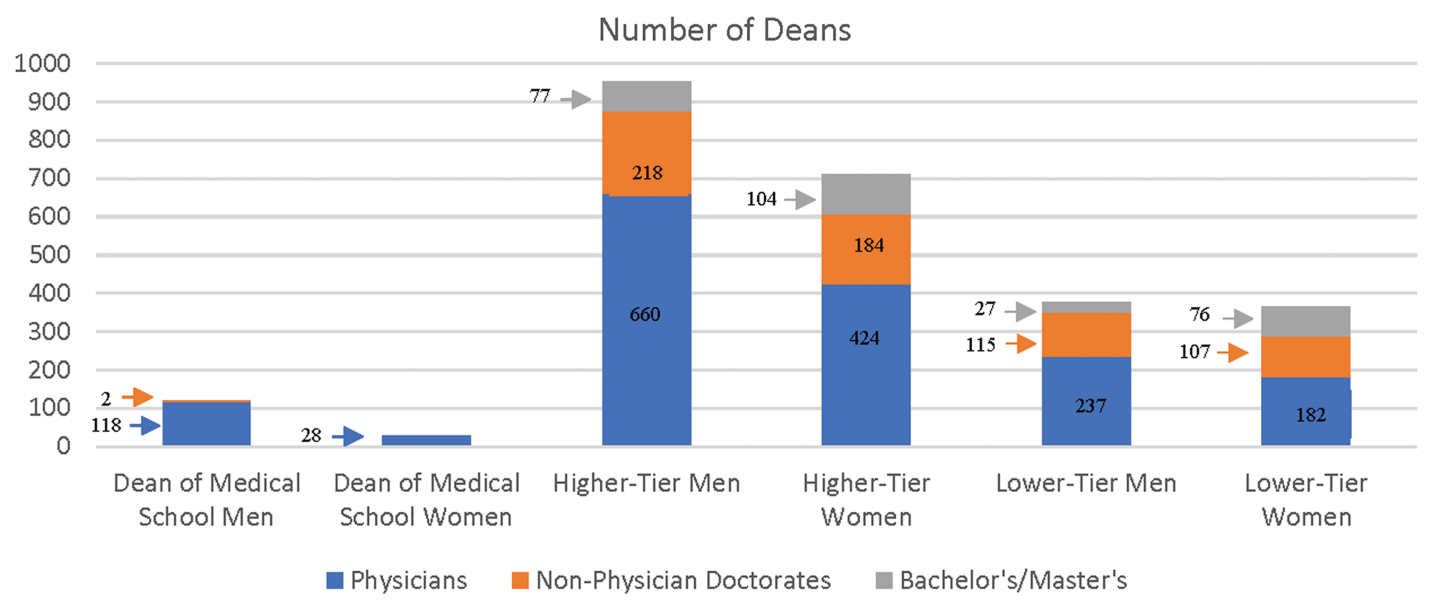

FIG. 3. Number of deans with each terminal degree, stratified by tier and gender. Color images are available online.

represented compared with men physicians. In comparison, women are over-represented among deans with terminal degrees at the bachelor's and master's level. In contrast, women nonphysician deans with doctorates occupy similar proportions of decanal roles to men deans at the level of vice dean and below. Disparities in the advancement of women physicians have been well established. ${ }^{8-10}$ The lack of representation of women physicians among deans is one of many factors that may impact the promotion of women physicians in academia.

Carr et al. followed 1273 faculty members for 17 years at 24 U.S. medical schools, and found that there were gender disparities in rank, retention, and leadership across the trajectory. ${ }^{8}$ Women were less likely to attain senior-level positions than men, even after adjusting for publication-related productivity. The authors recommended that institutions examine the climate for women to ensure that their academic capital is fully realized, and that they have equal opportunities for leadership roles. Other studies have also reported that women physicians have a lower rate of promotion to full professor after adjusting for age, experience, and metrics of research productivity. ${ }^{9,10}$

Women physicians are under-represented in other professional arenas, such as medical society awards, ${ }^{11,12}$ grand rounds lectureships, ${ }^{13}$ and presence on editorial boards. ${ }^{14}$ Historically, these disparities were explained as a "pipeline effect," and it was assumed by many people that as more women became physicians, they would be promoted equitably. ${ }^{15}$ However, more than a decade ago, researchers began to refute the pipeline as a reasonable explanation for leadership disparities. ${ }^{16}$ Progress in the advancement of women in academic medicine was inexplicably slow in spite of a large body of literature documenting disparities, ${ }^{17}$

Helitzer et al. refuted the theory of "critical mass.",3 This theory assumed that when women reached a $30 \%$ $35 \%$ threshold - critical mass-of representation among medical school faculty, the academic workforce culture would change and facilitate women's advancement. ${ }^{3}$ Instead of focusing on critical mass, Helitzer et al. suggested identifying "critical actors"-leaders who will actively improve the culture of academic medicine. Although these leaders may be people from across the gender spectrum and have a variety of terminal degrees, we suggest that it is important to promote transformational women physician leaders to the highest levels, and ensure that they are equitably represented.

In his presidential address to the American Surgical Association, Keith Lillemoe, MD, PhD noted that only one woman physician had served as president of the organization in its 137-year history. He said, "The number of outstanding, qualified female candidates is more than adequate to fill every open surgical leadership position in America today. The problem is not the pipeline-it is the process." 18

Our study highlights a hidden problem that may impact the culture of academic medical leadership. The ramifications of having a larger percentage of women with bachelor's and master's degrees in decanal roles are unknown. Physicians likely have a different network of colleagues and different skill sets compared with nonphysician deans without doctorates, though both skill sets are valuable for leadership. The medical

Table 2. Numbers of U.S. Allopathic Physician Deans in 2017 Stratified by Gender and Tier

\begin{tabular}{|c|c|c|c|}
\hline & Lower tier deans $\mathrm{s}^{\mathrm{a}}$ & Higher tier deans ${ }^{\mathrm{b}}$ & Deans of medical school \\
\hline Number of men deans & 379 & 955 & 120 \\
\hline Number of men physician deans (\%) & $237(62.5 \%)$ & $660(69.1 \%)$ & $118(98.3 \%)$ \\
\hline Number of women deans & 365 & 712 & 28 \\
\hline Number of women physician deans (\%) & $182(49.9 \%)$ & $424(59.6 \%)$ & $28(100 \%)$ \\
\hline $\begin{array}{l}\% \text { Men physician deans/\% women } \\
\text { physician deans }(p)\end{array}$ & $1.25(p=0.00065)$ & $1.16(p=0.000064)$ & $0.983(p=1)$ \\
\hline
\end{tabular}

${ }^{\mathrm{a}}$ Lower tier is the assistant dean category.

${ }^{\mathrm{b}}$ Higher tier includes associate, senior associate, and vice dean categories. 
setting is also distinct from a broader university setting, in that the learners are primarily $\mathrm{MD}$ and $\mathrm{PhD}$ candidates.

Files et al. studied a microinequality specific to academic medicine, the disparity in the introduction of women speakers by the title of "Dr." at departmental grand rounds. ${ }^{19}$ Professional titles based on training, as Files et al. say, "convey expertise and competence." 19 At Harvard Business School, Battilana and Casciaro described how both formal authority and informal networks influence how effective people are at their jobs. ${ }^{20}$ Formal authority is influenced by the amount and type of education and postgraduate training an individual completes.

The contributions of physicians and doctorate-level leaders to academic medicine compared with leaders with bachelor's and master's degrees have not been studied, but there may be important differences in the strengths, informal networks, and skill sets of each. The equitable representation of women physicians at all levels of academic leadership within medical schools is important to consider and study further.

Many ideas have been proposed to explain disparities, including gender stereotypes, ${ }^{2,21}$ prioritization of family needs, ${ }^{2,3,22-24}$ lack of adequate mentor networks, ${ }^{22,25,26}$ a culture of bias and discrimination, ${ }^{3,22,24,25}$ unequal access to resources, ${ }^{27}$ lack of self-promotion, ${ }^{15}$ and schedule inflexibility. ${ }^{26}$ Sponsorship has been cited as a critical element in career advancement, where a boss or other coworker who is in a position of authority actively advocates for a woman (or man) to be promoted or to receive other specific opportunities. This approach has been successful in the corporate world, and has been suggested as an approach for women in medicine. ${ }^{28}$

Some institutions have begun training programs on unconscious bias for the members of their promotions committee, as well as initiating career development programs ${ }^{29}$ and instituting flexible career plans ${ }^{30}$ aimed at fostering the careers of individual women. The Association of American Medical Colleges and National Institutes of Health have initiated mentorship and professional development programs for women. These programs have been found to improve retention of women faculty in academic medicine. ${ }^{23}$ Perhaps similar programs could be initiated for those interested in attaining decanal positions or ascending among the decanal ranks.

This study has several limitations. While the Bonferroni method keeps Type I error constant at 0.05 , it does so at the expense of inflating Type II error, ${ }^{31}$ thus there may be additional significant differences in our study that did not meet the threshold $p$-value. Of note, only one statistical test in our study yielded a result between 0.05 and 0.0026 .

Our data set is reflective of the accuracy of individual medical school websites as well as online biographical information. We determined an individual's gender preference to the best of our abilities using pronouns as a primary gender marker $95 \%$ of the time. If these were not available, we used a combination of name and photograph.

To facilitate data analysis, we grouped the deans into three broad categories; however, it is possible that a given title may hold a different position in the decanal hierarchy in various institutions. Osteopathic medical schools were not included in this study, and the data from these programs may differ.

Possible areas for future study include investigations of the reasons underlying the discrepancies reported in this study. Another area of potential investigation is the impact of women deans of medical schools on retention of women faculty and representation of women physicians and nonphysicians within decanal roles over time.

\section{Conclusions}

Women physicians occupy a significantly lower proportion of decanal roles compared with men physicians. While women as a whole are not under-represented at the lower tier dean level, women physicians do occupy a significantly lower proportion of these roles. Given the importance of decanal roles in academic medicine, further investigation is warranted.

\section{Author Disclosure Statement}

No competing financial interests exist for any of the authors.

\section{References}

1. White FS, McDade S, Yamagata H, Morahan PS. Genderrelated differences in the pathway to and characteristics of U.S. medical school deanships. Acad Med 2012;87:10151023.

2. Schor NF. The decanal divide: Women in decanal roles at U.S. medical schools. Acad Med 2018;93:237-240.

3. Helitzer DL, Newbill SL, Cardinali G, Morahan PS, Chang S, Magrane D. Changing the culture of academic medicine: Critical mass or critical actors? J Womens Health (Larchmt) 2017;26:540-548.

4. Association of American Medical Colleges. More women than men enrolled in U.S. medical schools in 2017. Available at: https://news.aamc.org/press-releases/article/applicantenrollment-2017 Accessed February 14, 2018.

5. Jolliff LJ, Coakley E, Sloane RA. Women in U.S. academic medicine and science: Statistics and benchmarking report 2011-2012. Available at: www.aamc.org/download/415556/ data/2011-2012wimsstatsreport.pdf Accessed February 18, 2018.

6. Jena AB, Olenski AR, Blumenthal DM. Sex differences in physician salary in US public medical schools. JAMA Intern Med 2016;176:1294-1304.

7. Silver JK, Slocum CS, Bank AM, et al. Where are the women? The underrepresentation of women physicians among recognition award recipients from medical specialty societies. PM R 2017;9:804-815.

8. Carr PL, Raj A, Kaplan SE, Terrin N, Breeze JL, Freund KM. Gender differences in academic medicine: Retention, rank, and leadership comparisons from the national faculty survey. Acad Med 2018;93:1694-1699.

9. Tesch BJ, Wood HM, Helwig AL, Nattinger AB. Promotion of women physicians in academic medicine. Glass ceiling or sticky floor? JAMA 1995;273:1022-1025.

10. Jena AB, Khullar D, Ho O, Olenski AR, Blumenthal DM. Sex differences in academic rank in US medical schools in 2014. JAMA 2015;314:1149-1158.

11. Silver JK, Bhatnagar S, Blauwet CA, et al. Female physicians are underrepresented in recognition awards from the American Academy of Physical Medicine and Rehabilitation. PM R 2017;9:976-984.

12. Silver JK, Blauwet CA, Bhatnagar S, et al. Women physicians are underrepresented in recognition awards from the Association of Academic Physiatrists. Am J Phys Med Rehabil 2018;97:34-40. 
13. Boiko JR, Anderson AJM, Gordon RA. Representation of women among academic grand rounds speakers. JAMA Intern Med 2017;177:722-724.

14. Amrein K, Langmann A, Fahrleitner-Pammer A, Pieber TR, Zollner-Schwetz I. Women underrepresented on editorial boards of 60 major medical journals. Gend Med 2011;8:378-387.

15. Rochon PA, Davidoff F, Levinson W. Women in academic medicine leadership: Has anything changed in 25 years? Acad Med 2016;91:1053-1056.

16. Carnes M, Morrissey C, Geller SE. Women's health and women's leadership in academic medicine: Hitting the same glass ceiling? J Womens Health (Larchmt) 2008;17: 1453-1462.

17. Bickel J. Women in medicine: Evidence that more evidence is insufficient in effecting improvements. Acad Med 2017; 92:274.

18. Lillemoe KD. Surgical mentorship: A great tradition, but can we do better for the next generation? Ann Surg 2017; 266:401-410.

19. Files JA, Mayer AP, Ko MG, et al. Speaker introductions at internal medicine grand rounds: Forms of address reveal gender bias. J Womens Health (Larchmt) 2017;26:413419.

20. Battilana J, Casciaro T. The network secrets of great change agents. Harv Bus Rev 2013;91:62-68.

21. Burgess DJ, Joseph A, van Ryn M, Carnes M. Does stereotype threat affect women in academic medicine? Acad Med 2012;87:506-512.

22. Talib Z, Burke KS, Barry M. Women leaders in global health. Lancet Glob Health 2017;5:e565-e566.

23. Chang S, Morahan PS, Magrane D, et al. Retaining faculty in academic medicine: the impact of career development programs for women. J Womens Health (Larchmt) 2016; 25:687-696.
24. Ellinas EH, Fouad N, Byars-Winston A. Women and the decision to leave, linger, or lean in: Predictors of intent to leave and aspirations to leadership and advancement in academic medicine. J Womens Health (Larchmt) 2017;27:324-332.

25. Edmunds LD, Ovseiko PV, Shepperd S, et al. Why do women choose or reject careers in academic medicine? A narrative review of empirical evidence. Lancet 2016;388: 2948-2958.

26. Bates C, Gordon L, Travis E, et al. Striving for gender equity in academic medicine careers: A call to action. Acad Med 2016;91:1050-1052.

27. Westring A, McDonald JM, Carr P, Grisso JA. An Integrated Framework for Gender Equity in Academic Medicine. Acad Med 2016;91:1041-1044.

28. Travis EL, Doty L, Helitzer DL. Sponsorship: A path to the academic medicine C-suite for women faculty? Acad Med 2013;88:1414-1417.

29. Carr PL, Gunn C, Raj A, Kaplan S, Freund KM. Recruitment, promotion, and retention of women in academic medicine: How institutions are addressing gender disparities. Womens Health Issues 2017;27:374-381.

30. Valantine H, Sandborg CI. Changing the culture of academic medicine to eliminate the gender leadership gap: 50/ 50 by 2020. Acad Med 2013;88:1411-1413.

31. Perneger TV. What's wrong with Bonferroni adjustments. BMJ 1998;316:1236-1238.

Address correspondence to: Allison R. Larson, MD

Department of Dermatology

Boston University

609 Albany St. J-207

Boston, $M A$

E-mail: arlarson@bu.edu 